\title{
sciendo
}

Transport and Telecommunication, 2019, volume 20, no. 4, 357-364

Transport and Telecommunication Institute, Lomonosova 1, Riga, LV-1019, Latvia

DOI 10.2478/ttj-2019-0029

\section{EFFECT OF PASSAGEWAY WIDTH ON PEDESTRIANS FLOW CHARACTERISTICS IN INTERCITY RAILWAY STATIONS}

\author{
Eswar Sala ${ }^{1}$, K.V.R. Ravishankar ${ }^{2}$ \\ Transportation Division, Department of Civil Engineering, \\ National Institute of Technology Warangal-506004, Telangana State, India, \\ Ieswar.sala@gmail.com \\ ${ }^{2}$ kvrrshankar@gmail.com
}

\begin{abstract}
Rail transportation is most economical means of the mode in comparison to road transportation. Intercity railway stations are nodal points of the rail network. With the growing demand and land use constraints, these are to be well planned, managed and designed. In intercity railways station infrastructure, passageways are confined and elevated elements for pedestrian movements to access among platforms to alight and board trains. Provision of appropriate width for passageway is of greater importance regarding comfort, convenient, evacuation, efficient, aesthetic, cost-effective, environment-friendly and well integrated with other elements of infrastructure. A proper understanding of pedestrian flow characteristics and affecting factors on passageway aids in design implications. In the present work, pedestrian flow characteristics variation on passageway and its width effect is studied. Results showed that, under normal conditions, flow rate $(\mathrm{ped} / \mathrm{m} / \mathrm{min})$ and mean walking speed $(\mathrm{m} / \mathrm{min})$ reduces with increase in width $(\mathrm{m})$. For a given flow rate, volume (ped/min) of pedestrians served on passageway increases with increase in width. Statistical tests revealed that there exists a significant difference in mean walking speed of pedestrians on passageways with different widths.
\end{abstract}

Keywords: Pedestrian, Flow Characteristics, Passageway, Width, Intercity railway station

\section{Introduction}

Opportunities and needs drive people to make trips to various places. Passengers make long hauling trips for various reasons via public transportation. Railways being the economical and fast means of access mode, a majority of passengers rely on rail transportation in developing countries like India. Intercity railway stations are nodal points in railway network. Passengers in intercity railway stations include heterogeneity with respect to physical, social and cultural aspects. They board and alight trains in intercity railway stations with different trip purpose, the frequency of trip making, group size, gender, age, and luggage. Intercity railway station infrastructure is to be well managed within the limited land available for the passenger's convenience, safe and easy access. In a comparison of foot over bridge (FOB) passageway with that of intercity railway station as a whole, it is the only means to access among various platforms. However, they have a choice between stairway and escalator to ascend FOB passageway.

A common passageway for passenger's bidirectional movement with differential flow ratios effects pedestrian flow characteristics. They become bottlenecks reducing free-flow speed and maximum flow (Rastogi and Chandra, 2013). Proper planning, design, and management let the best efficient use of infrastructure. Understanding pedestrian behaviour and factors affecting lets the planner in policy making and developing design standards. Analysis of pedestrian flow characteristics and model calibration forms bases for pedestrian simulation (Hongfei et al., 2009). A thorough revision of literature leads to understanding pedestrian behaviour and various factors affecting them.

Pedestrian flow characteristics are to be well understood, and design standards are to be modified before the use of foreign standards (Rahman et al., 2013). They vary by location, site, and region (Nazir et al., 2012; Tanaboriboon et al., 1986; Kawsar et al., 2017; Lam et al., 1995). Pedestrian studies on sidewalks, footpaths concluded that pedestrian flow characteristics are affected by culture and special events (Sukhadia et al., 2016). Free flow speed on passageway is double to that of stairway (Chen and Jian, 2010). Factors affecting pedestrian flow characteristics include pedestrian characteristics: age, gender, and luggage, environmental characteristics: climate, time of the study (Laxman et al., 2010), infrastructure characteristics: gradient of the facility (Al-Azzawi and Raeside, 2007). Pedestrians mean walking speed on stairways is greater than that of walkways (Liu et al., 2008). Walking speed of male pedestrians is greater than female pedestrians (Rastogi et al., 2010). Mean walking speed of pedestrians in 
descending directions is greater than that in ascending direction on stairway (Shah et al., 2013). Mean walking speed on daytime is greater than evening time (Shah et al., 2013). Flow ratio on stairways varies with train schedule, and directional distribution is found to be influencing pedestrian walking speed on stairway (Jiten et al., 2015a, 2015b). The flow rate and mean walking speed increases with an increase in width of stairway (Jiten et al., 2016). Artificial neural network performed better in comparison to conventional speed- density- flow models for the interrelationship between pedestrian flow characteristics on walkways and carriageways (Das et al., 2015). In many of these studies, pedestrian flow characteristics are studied on walkways, footpath, and stairway at various locations. Age, gender, time, train schedule, direction, flow ratio, gradient are found to be affecting pedestrian flow characteristics on stairways in metro train stations. Pedestrian flow studies on foot over bridges inside intercity railway stations are unnoticed. Pedestrians making long hauling journeys via intercity trains show up varied flow behaviour in comparison to metro trains, where they make short trips. Also, the aforesaid flow characteristics vary on the stairway to a passageway. Provision of an unscientific width of a passageway to a stairway for an anticipated flow rate of heterogeneous pedestrian traffic leads to non- uniform flow and create an accumulation of pedestrians on various infrastructure elements (stairway, escalator, and passageway) of foot over bridge. In this regard, there is a need to study the flow behaviour on level changing passageway inside intercity railway stations for a better management of existing passageways and to develop design standards for future expansion. This paper reflects the pedestrian flow behaviour on passageways in intercity railway stations, India. Also, a comparison of flow characteristics on passageways of different widths is made to understand the effect of the width of the passageway.

\section{Data collection}

Seven passageways from three intercity railway stations located along Secunderabad and Vijayawada corridor are falling under South Central railway zone of Indian railways is considered. Two passageways each of width $4.5 \mathrm{~m}$, one having a center rail to separate directional flow (to and fro) and other don't have, in Secunderabad railway station. One passageway of width $2.1 \mathrm{~m}$ in Warangal railway station. In Vijayawada, four passageways of widths 3.5, 2.3, 2.3 and 3.4m are considered.

Secunderabad (S) railway station is the capital of Telangana State, India. It has an integrated multimodal transport system (MMTS) facility. Warangal (W) Railway station is located in Warangal, capital of Warangal district, Telangana state, India. Vijayawada (V) railway station is located in the state of Andhra Pradesh, second biggest railway station in India. Table 1 shows the passageway dimensions in the three intercity railway stations considered for this study.

Table 1. Passageway dimensional details

\begin{tabular}{|c|c|c|c|c|c|c|c|}
\hline Description & $\begin{array}{c}\text { Secunderabad } \\
\left(\mathbf{S}_{\mathbf{p} 1}\right) \\
(\text { Without } \\
\text { Central rail) }\end{array}$ & $\begin{array}{c}\text { Secunderabad } \\
\left(\mathbf{S}_{\mathbf{p} 2}\right) \\
(\text { With Central } \\
\text { rail) }\end{array}$ & $\begin{array}{c}\text { Warangal } \\
\left(\mathbf{W}_{\mathbf{p} 1)}\right)\end{array}$ & $\begin{array}{c}\text { Vijayawada } \\
\left(\mathbf{V}_{\mathbf{p} 1)}\right.\end{array}$ & $\begin{array}{c}\text { Vijayawada } \\
\left(\mathbf{V}_{\mathbf{p} 2}\right)\end{array}$ & $\begin{array}{c}\text { Vijayawada } \\
\left(\mathbf{V}_{\mathbf{p} 3}\right)\end{array}$ & $\begin{array}{c}\text { Vijayawada } \\
\left(\mathbf{V}_{\mathbf{p} 4}\right)\end{array}$ \\
\hline Length (m) & 14 & 14 & 25.7 & 17.8 & 17.8 & 58.1 & 28.4 \\
\hline Width (m) & 4.5 & 4.5 & 2.1 & 3.5 & 2.3 & 2.3 & 3.4 \\
\hline
\end{tabular}

Video recording technique is used for data collection. It provides permanent data; aids in a large number of data point extraction, observe and track pedestrian's movement. On each passageway, three hours of video is recorded. In the later stage, pedestrian traffic parameters flow, density and speed are determined from playback videos in Media Classic Player. Figure 1 shows the snapshots of video recording data collected on each passageway in Secunderabad, Warangal and Vijayawada railway stations.

On each passageway, directional pedestrian volume crossing a reference line is counted for each minute. Directional flow is calculated as a ratio of volume in a direction to the width of the facility per minute. With two references lines fixed of known length, time taken to cross the two reference line to the nearest millisecond is noted. His/her walking speed is determined as a ratio of distance between two reference lines to the time taken to cross. Mean walking speed is taken as the average of pedestrians walking speed in a particular minute. To determine the pedestrian density for a minute, playback video is paused, and the number of pedestrians present between two reference lines is manually counted. Density is calculated as a ratio of the pedestrian count to the area (length between references lines multiplied by the width of the facility). 


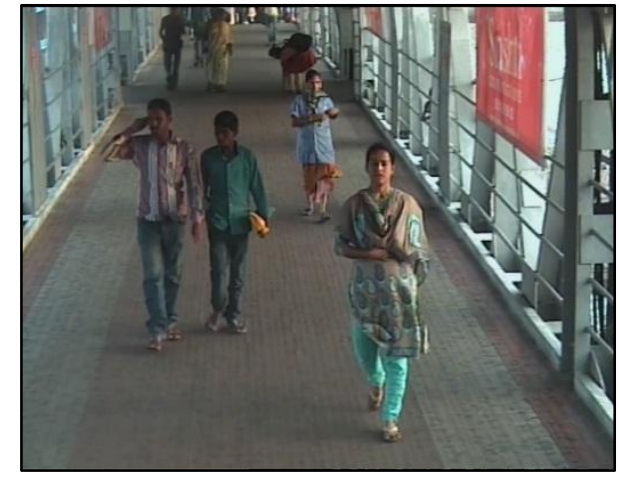

1(a): $S_{P 1}-$ Secunderabad without central rail

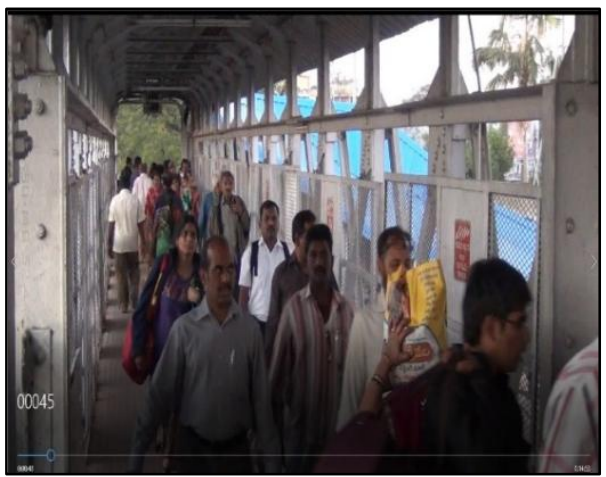

1(c): $\mathrm{W}_{\mathrm{P} 1}-$ Warangal

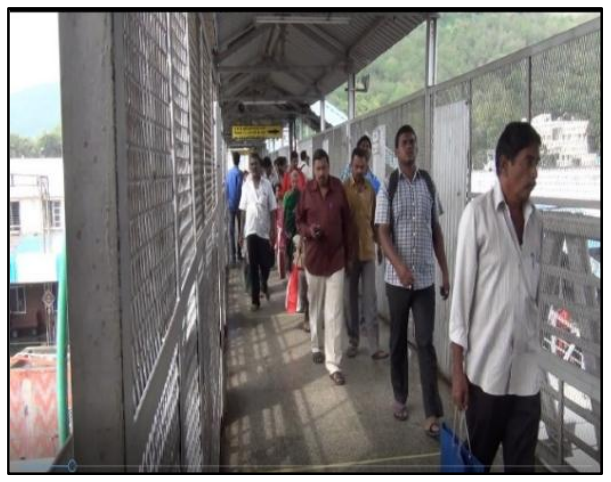

1(e): $\mathrm{V}_{\mathrm{P} 2}-$ Vijayawada passageway

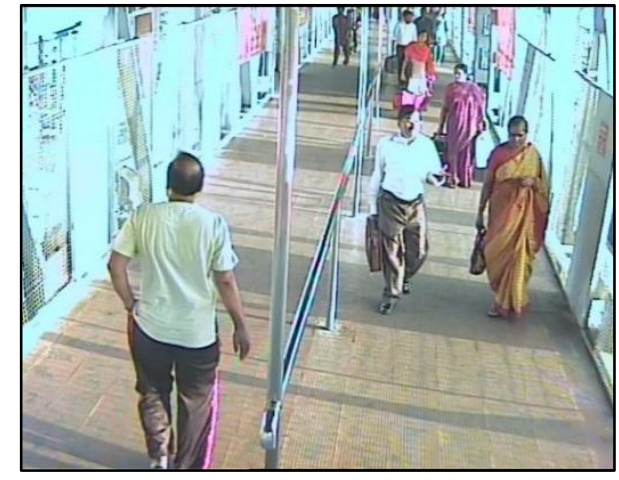

1(b): $\mathrm{S}_{\mathrm{P} 2}-$ Secunderabad with central Rail

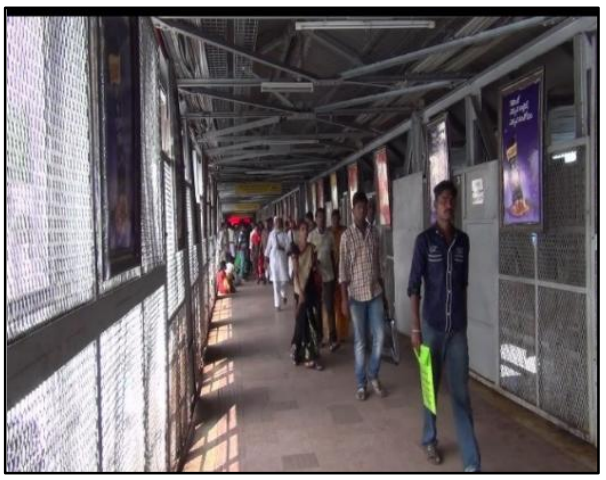

1(d): $V_{P 1}$ - Vijayawada passageway 1

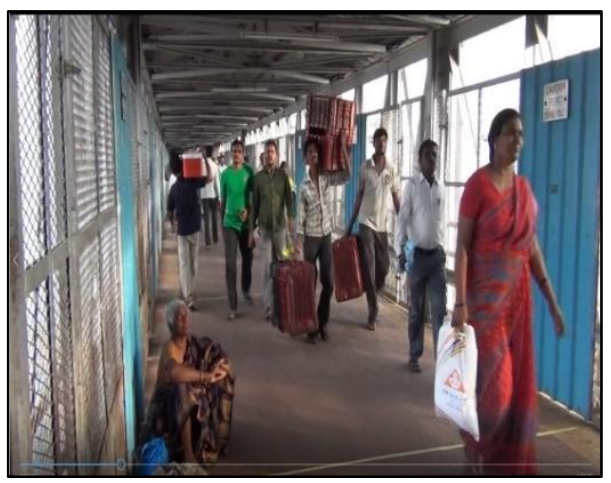

1(f): $V_{P 3}-$ Vijayawada passageway

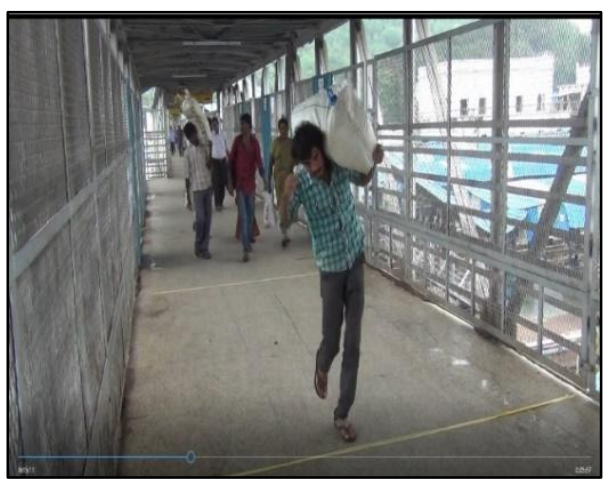

1(g): $\mathrm{V}_{\mathrm{P} 4^{-}}$Vijayawada passageway

Figure 1. Snapshots of passageways in intercity railway stations 


\section{Pedestrian flow characteristics and variation with width of passageway}

Pedestrian flow characteristic plots, flow-density-space, are plotted for the extracted data points for the observed seven passageways from Secunderabad, Warangal, and Vijayawada intercity railway stations. Figure 2 shows the flow-density (2a) and flow- space (2b) plots. Second-degree polynomial trend line fits for flow- density and flow- space showed an exponential trend. Table 2 shows the fitted trend line equations with respective $\mathrm{R}^{2}$ value and observed pedestrian flow characteristics on each passageway are tabulated in table 3.

The passageway in Secunderabad railway station has relatively lower values of pedestrian flow characteristics with the highest width among the observed passageways. As Secunderabad railway station has integrated MMTS facility operated, there are relatively considerable daily commuters. Hence pedestrian flow on passageway is observed to be affected by the side friction caused by other waiting pedestrians.

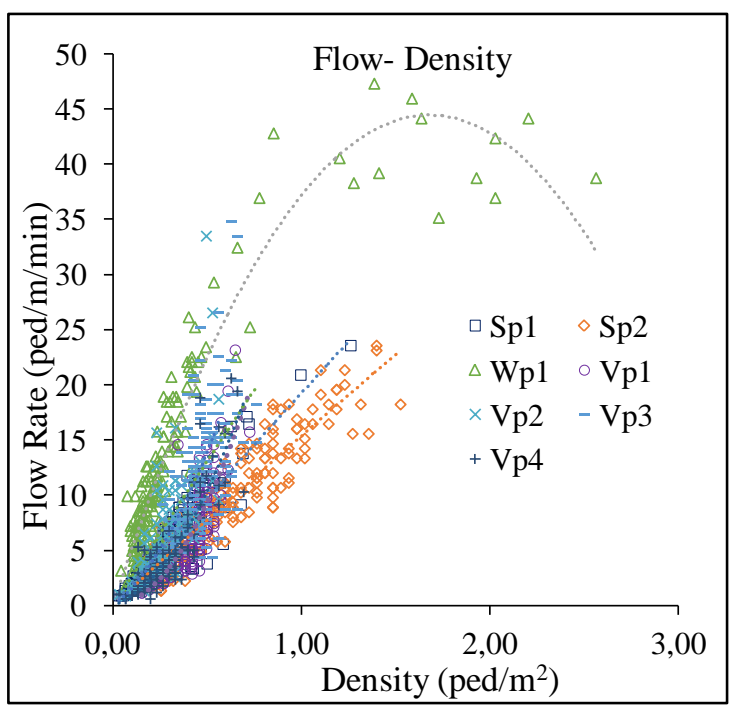

2(a): Flow Rate- Density

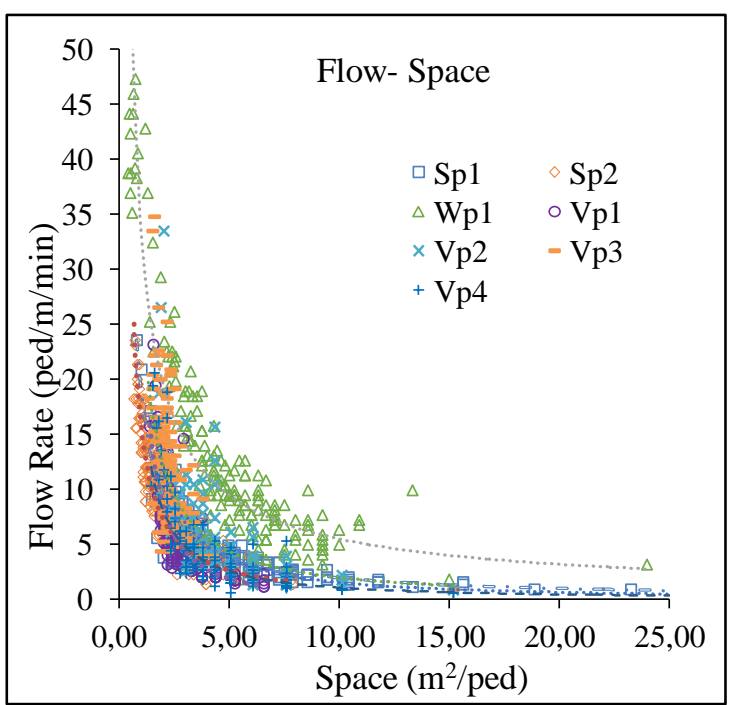

2(b): Flow Rate- Space

Figure 2. Flow Rate- Density- Space Plots of Observed Pedestrian Traffic on Passageways

Table 2. Flow - Density- Space- Speed trend line equations with respective $\mathrm{R}^{2}$

\begin{tabular}{|c|c|c|}
\hline Station & Description & $\mathbf{R}^{2}$ \\
\hline \multicolumn{3}{|c|}{ Flow - Density } \\
\hline $\mathrm{S}_{\mathrm{p} 1}$ & $y=-0.4814 x^{2}+19.735 x$ & 0.8445 \\
\hline $\mathrm{S}_{\mathrm{p} 2}$ & $y=-0.3921 x^{2}+15.761 x$ & 0.8651 \\
\hline $\mathrm{W}_{\mathrm{p} 1}$ & $y=-15.774 x^{2}+52.957 x$ & 0.9102 \\
\hline $\mathrm{V}_{\mathrm{p} 1}$ & $y=36.082 x^{2}+0.6544 x$ & 0.6665 \\
\hline $\mathrm{V}_{\mathrm{p} 2}$ & $y=29.83 x^{2}+12.912 x$ & 0.5691 \\
\hline $\mathrm{V}_{\mathrm{p} 3}$ & $y=-0.2332 x^{2}+26.241 x$ & 0.2708 \\
\hline $\mathrm{V}_{\mathrm{p} 4}$ & $y=29.832 x^{2}+5.8908 x$ & 0.7720 \\
\hline \multicolumn{3}{|c|}{ Flow - Space } \\
\hline $\mathrm{S}_{\mathrm{p} 1}$ & $y=18.779 x^{-0.988}$ & 0.8729 \\
\hline $\mathrm{S}_{\mathrm{p} 2}$ & $y=15.689 x^{-1.113}$ & 0.8410 \\
\hline $\mathrm{W}_{\mathrm{p} 1}$ & $y=33.639 x^{-0.788}$ & 0.7804 \\
\hline $\mathrm{V}_{\mathrm{p} 1}$ & $y=26.94 x^{-1.664}$ & 0.7305 \\
\hline $\mathrm{V}_{\mathrm{p} 2}$ & $y=28.469 x^{-1.274}$ & 0.7364 \\
\hline $\mathrm{V}_{\mathrm{p} 3}$ & $y=26.976 x^{-1.136}$ & 0.4104 \\
\hline $\mathrm{V}_{\mathrm{p} 4}$ & $y=19.141 x^{-1.259}$ & 0.7440 \\
\hline
\end{tabular}


The passageway in Warangal $\left(\mathrm{W}_{\mathrm{p} 1}\right)$ of width $2.1 \mathrm{~m}$ showed higher flow rate $(48 \mathrm{ped} / \mathrm{m} / \mathrm{min}$ ) of all the passageways. Warangal has two foot over bridges for pedestrian access, one located in the middle of platform nearer to the entry/exit of the station and other at one end of the platform. Pedestrians tend to use infrastructure nearer to entry/exit in higher proportion in comparison to the facility at other location. This lead to the higher use of the passageway nearer to entry/exit in more number in comparison to the other passageways at other locations.

Four passageways are considered in Vijayawada railway station. It has four passageways connecting platforms and two entry/exit location. Moreover distributed ticketing services at various places lead to the distribution of pedestrian flow on foot over bridges. Hence relatively lower flow rates are observed in this case. It is evident that the flow rate on $\mathrm{V}_{\mathrm{p} 2}(33 \mathrm{ped} / \mathrm{m} / \mathrm{min})$ and $\mathrm{V}_{\mathrm{p} 3}(35 \mathrm{ped} / \mathrm{m} / \mathrm{min})$ are the almost equal width $(2.3 \mathrm{~m})$. While on $\mathrm{V}_{\mathrm{p} 1}$ and $\mathrm{V}_{\mathrm{p} 4}$, flow rates $(23 \mathrm{ped} / \mathrm{m} / \mathrm{min})$ and $(21 \mathrm{ped} / \mathrm{m} / \mathrm{min})$ respectively, are nearly equal for almost equal widths. Hence for a given station, flow rate varies with width of passageway. Secunderabad has almost an equal maximum flow rate for the passage with and without central rail for directional flow separation.

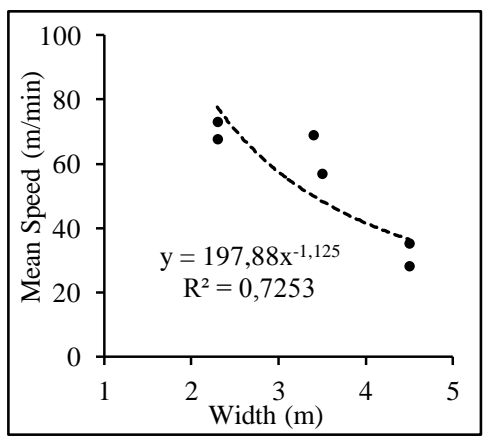

3(a): Maximum Flow rate- Width

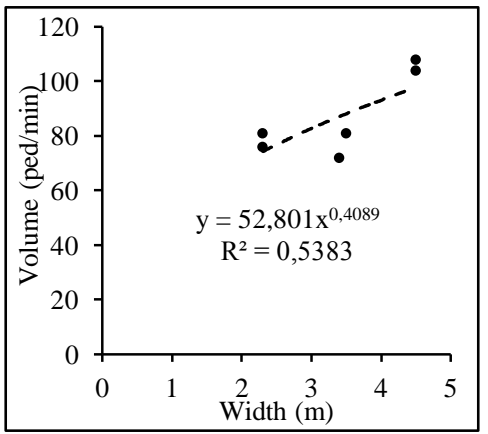

3(b): Mean Speed- Width

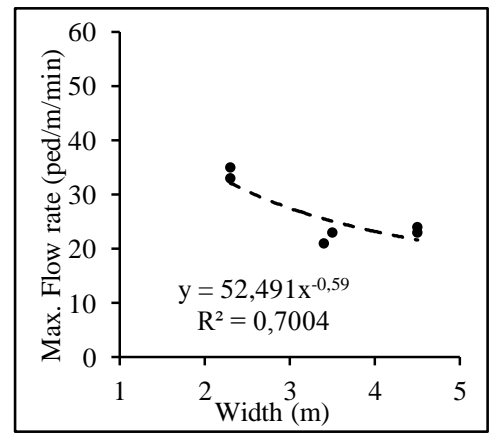

3(c): Volume- Width

Figure 3. Maximum Flow Rate, Mean Walking Speed and Volume of Pedestrian's Variation with Width of Passageways

Variation of flow with the width of passageway $\mathrm{S}_{\mathrm{p} 1}, \mathrm{~S}_{\mathrm{p} 2}, \mathrm{~V}_{\mathrm{p} 1}, \mathrm{~V}_{\mathrm{p} 2}, \mathrm{~V}_{\mathrm{p} 3}$ and $\mathrm{V}_{\mathrm{p} 4}$, figure $3(\mathrm{a})$, shows that the maximum flow rate $(\mathrm{ped} / \mathrm{m} / \mathrm{min})$ reduces with increase in width and stabilizes at greater width. It is asserted to the distribution of pedestrians with width. It can be concluded that with the increase in width, flow rate decreases and attains equilibrium at widths ranging $3.5 \mathrm{~m}$ to $4.5 \mathrm{~m}$. Pedestrians mean walking speed variation with the width of the passageway, figure 3(b), reflects a reduction in mean pedestrian walking speed with an increase in width and tends to stabilize at greater width. Comparing the flow and speed variation with width acknowledge that, at lower widths pedestrians are packed such that they have no choice of choosing their desired speed with their attributes like age, gender, luggage and tends to follow the lead pedestrian. Also at lower widths, pedestrians tend to get out of the congested confined area and hence walk with a higher walking speed than on passageways with higher widths. Critical density increases with increase in width of the passageway and stabilized at higher width.

From the table 3 and figure 3(c), Comparison of width with the volume of pedestrians it serves at the observed maximum flow rate, it signifies that the pedestrian volume increases with increases in the width of the passageway. Considering the passageway flow rates on $S_{p 1}, S_{p 2} V_{p 1}$ and $V_{p 4}$ which are in close range, it can be stated that for a given flow rate, volume ( $\mathrm{ped} / \mathrm{min}$ ) of pedestrians served on passageway increases with increase in width.

To understand the variation of flow characteristics on passageways with width within a station, $\mathrm{V}_{\mathrm{p} 1}, \mathrm{~V}_{\mathrm{p} 2}, \mathrm{~V}_{\mathrm{p} 3}$, and $\mathrm{V}_{\mathrm{p} 4}$ at Vijayawada station are considered. For a given station characteristics and anticipated pedestrian demand, flow rate reduces with an increase in width.

Table 3. Pedestrians flow characteristics on passageway

\begin{tabular}{|l|l|l|l|l|l|l|l|}
\hline Description & $\mathbf{S}_{\mathbf{P} 1}$ & $\mathbf{S}_{\mathbf{P} 2}$ & $\mathbf{W}_{\mathbf{P 1}}$ & $\mathbf{V}_{\mathbf{P 1}}$ & $\mathbf{V}_{\mathbf{P} 2}$ & $\mathbf{V}_{\mathbf{P 3}}$ & $\mathbf{V}_{\mathbf{P 4}}$ \\
\hline Width (m) & 4.5 & 4.5 & 2.1 & 3.5 & 2.3 & 2.3 & 3.4 \\
\hline Max Flow rate (ped/m/min) & 24 & 23 & 48 & 23 & 33 & 35 & 21 \\
\hline $\begin{array}{l}\text { Volume (ped/min) at Max } \\
\text { flow rate (rounded off to } \\
\text { nearest whole number) }\end{array}$ & 108 & 104 & 101 & 81 & 76 & 81 & 72 \\
\hline
\end{tabular}




\begin{tabular}{|l|l|l|l|l|l|l|l|}
\hline Description & $\mathbf{S}_{\mathbf{P} 1}$ & $\mathbf{S}_{\mathbf{P} 2}$ & $\mathbf{W}_{\mathbf{P 1}}$ & $\mathbf{V}_{\mathbf{P} 1}$ & $\mathbf{V}_{\mathbf{P} 2}$ & $\mathbf{V}_{\mathbf{P} 3}$ & $\mathbf{V}_{\mathbf{P} 4}$ \\
\hline Critical density $\left(\mathrm{ped} / \mathrm{m}^{2}\right)$ & 1.25 & 1.4 & 1.4 & 0.72 & 0.56 & 0.76 & 0.69 \\
\hline Space available $\left(\mathrm{m}^{2} / \mathrm{ped}\right)$ & 0.8 & 0.72 & 0.62 & 1.54 & 2.02 & 1.60 & 1.60 \\
\hline Mean Speed $(\mathrm{m} / \mathrm{min})$ & 35.25 & 28.19 & 66.53 & 56.90 & 73.04 & 67.67 & 68.92 \\
\hline Free flow speed $(\mathrm{m} / \mathrm{min})$ & 39.00 & 31.80 & 75.00 & 58.80 & 85.20 & 71.40 & 70.20 \\
\hline Critical speed $(\mathrm{m} / \mathrm{min})$ & 21.00 & 15.60 & 36.00 & 30.00 & 33.60 & 34.20 & 39.60 \\
\hline
\end{tabular}

\section{Effect of passageway width on pedestrian walking speed}

A statistical t-test is conducted in Statistical Package for the Social Sciences (SPSS) software at 95\% confidence level. Null and alternate hypotheses respectively are assumed to be as

$H_{o} ; \mu_{\text {Passageway } 1}=\mu_{\text {Passageway } 2}$,

$H_{1} ; \mu_{\text {Passageway } 1} \neq \mu_{\text {Passageway } 2}$,

where $\mu$ is the pedestrians mean walking speed on passageway here. Levene's test for equality of variances is considered for the acceptance and rejection of assumed equal variance with significance value, $\alpha=0.05$. The calculated $p$-value is compared with $\alpha$. If $p \leq \alpha$, the null hypothesis is rejected thereby resulting in that there exists a significant difference in pedestrians walking speed on passageways of different widths (Using SPSS for t Tests, 2017).

Table 4 shows the t-test results for the various combinations of pedestrian walking speed on observed passageways. Keen look into the results, it can be drawn that there exists a significant difference in pedestrian walking speed on passageways with different widths.

Considering passageways with and without central rail (Sp1 and Sp2 respectively) for directional flow separation, for equal width $4.5 \mathrm{~m}$, there existed a significant difference in pedestrian walking speed. Pedestrian flow in intercity railway stations is of such a kind that the flow in the direction of a platform to which train arrives will have greater flow before the arrival and the flow in other direction increases after the arrival of the train on to the platform. Pedestrians have the feasibility to use the entire width of a passageway in the absence of central railing. While in case of the passageway with central railing, because of the confinement of flow to the respective side of the central rail, pedestrian density increased thereby leading to the reduction in mean walking speed. Hence there existed a significant difference in pedestrian walking speed on passageway with and without a central rail for equal width.

Table 4. Statistical test results of width effect on pedestrian mean walking speed

\begin{tabular}{|c|c|c|c|c|c|c|c|c|c|}
\hline Stairway Combination & n1 & n2 & $\mu 1$ & $\mu 2$ & f & sig & $\mathbf{t}$ & sig & Significance \\
\hline $\mathrm{S}_{\mathrm{P} 1}-\mathrm{S}_{\mathrm{P} 2}$ & 180 & 180 & 35.25 & 28.19 & 5.606 & 0.018 & 13.166 & 0.000 & $\mathrm{~S}$ \\
\hline $\mathrm{S}_{\mathrm{P} 1}-\mathrm{W}_{\mathrm{P1}}$ & 180 & 170 & 35.25 & 66.53 & 68.377 & 0.000 & -26.649 & 0.000 & $\mathrm{~S}$ \\
\hline $\mathrm{S}_{\mathrm{P} 1}-\mathrm{V}_{\mathrm{P} 1}$ & 180 & 177 & 35.25 & 56.90 & 23.664 & 0.000 & -28.633 & 0.000 & $\mathrm{~S}$ \\
\hline $\mathrm{S}_{\mathrm{P} 1}-\mathrm{V}_{\mathrm{P} 2}$ & 180 & 158 & 35.25 & 73.04 & 35.162 & 0.000 & -44.496 & 0.000 & $\mathrm{~S}$ \\
\hline $\mathrm{S}_{\mathrm{P} 1}-\mathrm{V}_{\mathrm{P} 3}$ & 180 & 145 & 35.25 & 67.67 & 22.428 & 0.000 & -40.830 & 0.000 & $\mathrm{~S}$ \\
\hline $\mathrm{S}_{\mathrm{P} 1}-\mathrm{V}_{\mathrm{P} 4}$ & 180 & 154 & 35.26 & 68.92 & 37.331 & 0.000 & -38.225 & 0.000 & $\mathrm{~S}$ \\
\hline $\mathrm{S}_{\mathrm{P} 2} \cdot \mathrm{W}_{\mathrm{P} 1}$ & 180 & 170 & 28.19 & 66.53 & 96.575 & 0.000 & -33.758 & 0.000 & $\mathrm{~S}$ \\
\hline $\mathrm{S}_{\mathrm{P} 2}-\mathrm{V}_{\mathrm{P} 1}$ & 180 & 177 & 28.19 & 56.90 & 57.041 & 0.000 & -41.276 & 0.000 & $\mathrm{~S}$ \\
\hline $\mathrm{S}_{\mathrm{P} 2}-\mathrm{V}_{\mathrm{P} 2}$ & 180 & 158 & 28.19 & 73.04 & 72.878 & 0.000 & -56.359 & 0.000 & $\mathrm{~S}$ \\
\hline $\mathrm{S}_{\mathrm{P} 2}-\mathrm{V}_{\mathrm{P} 3}$ & 180 & 145 & 28.19 & 67.67 & 58.445 & 0.000 & -53.600 & 0.000 & $\mathrm{~S}$ \\
\hline $\mathrm{S}_{\mathrm{P} 2}-\mathrm{V}_{\mathrm{P} 4}$ & 180 & 154 & 28.19 & 68.92 & 74.35 & 0.000 & -49.108 & 0.000 & $\mathrm{~S}$ \\
\hline $\mathrm{W}_{\mathrm{P} 1}-\mathrm{V}_{\mathrm{P} 1}$ & 180 & 177 & 66.53 & 56.90 & 24.931 & 0.000 & 7.674 & 0.000 & $\mathrm{~S}$ \\
\hline $\mathrm{W}_{\mathrm{P} 1}-\mathrm{V}_{\mathrm{P} 2}$ & 180 & 158 & 66.53 & 73.04 & 14.353 & 0.000 & -4.955 & 0.000 & $\mathrm{~S}$ \\
\hline $\mathrm{W}_{\mathrm{P} 1}-\mathrm{V}_{\mathrm{P} 3}$ & 170 & 145 & 66.53 & 67.67 & 22.364 & 0.000 & -0.891 & 0.373 & NS \\
\hline $\mathrm{W}_{\mathrm{P} 1}-\mathrm{V}_{\mathrm{P} 4}$ & 170 & 154 & 66.53 & 68.92 & 12.041 & 0.001 & -1.789 & 0.075 & NS \\
\hline $\mathrm{V}_{\mathrm{P} 1}-\mathrm{V}_{\mathrm{P} 2}$ & 177 & 158 & 56.90 & 73.04 & 1.747 & 0.187 & -16.946 & 0.000 & $\mathrm{~S}$ \\
\hline
\end{tabular}




\begin{tabular}{|l|l|l|l|l|l|l|l|l|l|}
\hline Stairway Combination & $\mathbf{n 1}$ & $\mathbf{n 2}$ & $\boldsymbol{\mu 1}$ & $\boldsymbol{\mu} \mathbf{2}$ & $\mathbf{f}$ & sig & $\mathbf{t}$ & sig & Significance \\
\hline $\mathrm{V}_{\mathrm{P} 1}-\mathrm{V}_{\mathrm{P} 3}$ & 177 & 145 & 56.90 & 67.67 & 0.009 & 0.926 & -11.808 & 0.000 & $\mathrm{~S}$ \\
\hline $\mathrm{V}_{\mathrm{P} 1}-\mathrm{V}_{\mathrm{P} 4}$ & 177 & 154 & 56.90 & 68.92 & 2.666 & 0.103 & -12.307 & 0.000 & $\mathrm{~S}$ \\
\hline $\mathrm{V}_{\mathrm{P} 2}-\mathrm{V}_{\mathrm{P} 3}$ & 158 & 145 & 73.04 & 67.67 & 1.884 & 0.171 & 5.399 & 0.000 & $\mathrm{~S}$ \\
\hline $\mathrm{V}_{\mathrm{P} 2}-\mathrm{V}_{\mathrm{P} 4}$ & 158 & 154 & 73.04 & 68.92 & 0.106 & 0.745 & 3.891 & 0.000 & $\mathrm{~S}$ \\
\hline $\mathrm{V}_{\mathrm{P} 3}-\mathrm{V}_{\mathrm{P} 4}$ & 145 & 154 & 67.67 & 68.92 & 2.782 & 0.096 & -1.222 & 0.223 & $\mathrm{NS}$ \\
\hline
\end{tabular}
NS - Not Significant.

\section{Conclusions}

Planning and management of infrastructure in an intercity railway stations with resource constraints is of great challenge. Analysis of pedestrian flow characteristics on respective elements of infrastructure is the primary key to plan and designing new facility and maintenance of existing facility. A passageway is one such element which is a confined area and grade separated with the platform for pedestrian access to alight and board trains on various platforms. Width is a primary variable which affects the pedestrian flow characteristics. Understanding the effect of width on pedestrian walking speed at normal conditions helps in attaining at the appropriate width required for an anticipated pedestrian demand in an intercity railway station.

In the present research, seven passageways of varying infrastructure characteristics are considered to understand the effect of width on pedestrian flow characteristics under normal conditions. From the results, it can be concluded that the flow rate and mean walking speed reduces with increase in width and attains stability at greater widths. Critical density reduces with increase in width of a passageway and attains equilibrium at higher width. For a given flow rate, volume (ped $/ \mathrm{min}$ ) of pedestrians served on passageway increases with increase in width. For a given station characteristics, flow rate reduces with an increase in width of the passageway. A statistical t-test is conducted in SPSS to study the effect of passageway width on pedestrians mean walking speed. There existed a significant difference in mean walking speed of pedestrians on passageways for different widths. It can be concluded that width significantly affects pedestrian flow characteristics on passageway of a foot over bridge in an intercity railway station. At lower widths, pedestrians feel congested, inconvenience and tend to exit the confined section. Pedestrians follow the flow speed and do not have a choice to choose desired speed. At greater widths, pedestrians have greater space available and walk with the desired speed with respect to selfcharacteristic age, gender, and luggage. It can be concluded that at lower widths, pedestrian flow characteristics are predominant while at higher widths pedestrian attributes are dominant in one's walking speed.

This study has some limitations. Pedestrian attributes- age, gender, luggage, trip purpose are not considered in this present research work. Further location of passageway is also to be studied to understand the pedestrian flow distribution proportions and flow characteristics variation on various foot over bridges with in a station. In spite of these limitations, present research has identified the variation in pedestrian flow characteristics with width of the passageway in an intercity railway station. This study results can be used as an input to simulation and understand the pedestrian breakdown and capacity of passageway with width.

\section{Acknowledgement}

This research study was funded by Science and Engineering Research Board, Department of Science and Technology, Government of India under "Fast Track Young Scientist-Engineering Science Scheme" with project designations SERB/F/1821/2014-2015 dated $18^{\text {th }}$ June, 2014. Authors express their thanks and appreciation to the research project panel for their insightful comments and sanctioning of the project.

We would like to extend our sincere gratitude to South Central Railway Officials for their cooperation in data collection.

\section{References}

1. Rastogi, R., and Chandra, S. (2013) Pedestrian flow characteristics for different pedestrian facilities and situations. European Transport, 53, paper 6. 
2. Hongfei, J., Lili, Y., and Ming, T. (2009) Pedestrian flow characteristics analysis and model parameter calibration in comprehensive transport terminal. Journal of Transportation Systems Engineering and Information Technology, 9(5), 117-123. DOI:10.1016/S1570-6672(08)60082-3.

3. Rahman, K., Ghani, N. A., Kamil, A. A., and Mustafa, A. (2013) Weighted regression method for the study of pedestrian flow characteristics in Dhaka, Bangladesh. Modern Applied Science, 7(4), 17. DOI:10.5539/mas.v7n4p17.

4. Nazir, M. I., Adhikary, S. K., Hossain, Q. S., and Ali, S. A. (2012) Pedestrian flow characteristics in Khulna metropolitan city, Bangladesh. Journal of Engineering Science, 3(1), 25-31.

5. Tanaboriboon, Y., Hwa, S., and Chor, C. (1986) Pedestrian Characteristics Study in Singapore. Journal of Transportation Engineering, 112(3), 229-235. DOI:10.1061/(asce)0733-947x(1986)112:3(229).

6. Kawsar, L., Ghani, N., Kamil, A., and Mustafa, A. (2017) An Improved Speed-Density Relationship Model for Pedestrian Flow. American Journal of Applied Sciences, 14(1), 184-203. DOI:10.3844/ajassp.2017.184.203.

7. Lam, W. H., Morrall, J. F., and Ho, H. (1995) Pedestrian flow characteristics in Hong Kong. Transportation Research Record, 1487, 56-62.

8. Sukhadia, H., Dave, S., Shah, J., and Rathva, D. (2016) The Effect of Events on Pedestrian Behavior and its Comparison with Normal Walking Behaviour in CBD Area in Indian Context. Transportation Research Procedia, 17, 653-663. DOI:10.1016/j.trpro.2016.11.120.

9. Chen, X., Ye, J., and Jian, N. (2010) Relationships and Characteristics of Pedestrian Traffic Flow in Confined Passageways. Transportation Research Record: Journal of the Transportation Research Board, 2198(1), 32-40. DOI:10.3141/2198-05.

10. Laxman, K., Rastogi, R., and Chandra, S. (2010) Pedestrian Flow Characteristics in Mixed Traffic Conditions. Journal of Urban Planning and Development, 136(1), 23-33. DOI:10.1061/(asce)07339488(2010)136:1(23)

11. Al-Azzawi, M., and Raeside, R. (2007) Modelling Pedestrian Walking Speeds on Sidewalks. Journal of Urban Planning and Development, 133(3), 211-219. DOI:10.1061/(asce)0733-9488(2007)133:3(211)

12. Liu, W., Zhou, H., and He, Q. (2008) Modelling pedestrians flow on stairways in Shanghai metro transfer station. In: 2008 International Conference on Intelligent Computation Technology and Automation. IEEE, 263-267.

13. Rastogi, R., Thaniarasu, I., and Chandra, S. (2010) Design Implications of Walking Speed for Pedestrian Facilities. Journal of Transportation Engineering, 137(10), 687-696. DOI:10.1061/(asce)te.1943-5436.0000251.

14. Shah, J., Joshi, G., and Parida, P. (2013) Walking Speed of Pedestrian on Stairways at Intercity Railway Station in India. In: Proceedings of the Eastern Asia Society for Transportation Studies, 9.

15. Shah, J., Joshi, G., and Parida, P. (2013) Behavioral Characteristics of Pedestrian Flow on Stairway at Railway Station. Procedia - Social and Behavioral Sciences, 104, 688-697. DOI:10.1016/j.sbspro.2013.11.163.

16. Jiten, S., Gaurang, J., Purnima, P., and Shriniwas, A. (2015a) Analysis of Commuter Flow Behaviour on Stairways at Metropolitan Transit Station in Mumbai, India. International Journal for Traffic and Transport Engineering, 5(4). DOI:10.7708/ijtte.2015.5(4).09.

17. Jiten, S., Gaurang, J., Purnima, P., and Shriniwas, A. (2015b) Impact of Train Schedule on Pedestrian Movement on Stairway at Suburban Rail Transit Station in Mumbai, India. Advances in Civil Engineering, 2015, 1-9. DOI:10.1155/2015/297807.

18. Jiten, S., Gaurang, J., Purnima, P., and Arkatkar, S. (2016) Effect of stairway width on pedestrian flow characteristics at railway stations. Transportation Letters, 8(2), 98-112. DOI:10.1179/1942787515y.0000000012.

19. Das, P., Parida, M., and Katiyar, V. (2015) Analysis of interrelationship between pedestrian flow parameters using artificial neural network. Journal of Modern Transportation, 23(4), 298-309. DOI:10.1007/s40534-015-0088-9.

20. Using SPSS for t Tests. https://academic.udayton.edu/gregelvers/psy216/spss/ttests.htm. Accessed 10 November 2017. 